ARTICLE OPEN \title{
Corrosion behavior of an in situ consolidated nanocrystalline
} Al-V alloy

\author{
C. S. Witharamage $\mathbb{D}^{1}$, J. Christudasjustus $\mathbb{D}^{1}$, J. Smith ${ }^{1}$, W. Gao ${ }^{1}$ and R. K. Gupta $\mathbb{D}^{1 凶}$
}

Supersaturated solid solutions of $\mathrm{Al}$ and corrosion-resistant alloying elements ( $\mathrm{M}: \mathrm{V}, \mathrm{Mo}, \mathrm{Cr}, \mathrm{Ti}, \mathrm{Nb})$, produced by non-equilibrium processing techniques, have been reported to exhibit high corrosion resistance and strength. The corrosion mechanism for such improved corrosion performance has not been well understood. We present a fundamental understanding of the role of $\mathrm{V}$ in corrosion of an Al-V alloy, which will provide a theoretical background for developing corrosion-resistant Al alloys. High-energy ball milling of the elemental powder of Al and V produced an in situ consolidated Al-V alloy, which exhibited high solid solubility of V. The corrosion resistance of Al-V alloy was significantly higher than that of pure Al, which was attributed to the (1) enrichment of $\mathrm{V}$ at the passive film/substrate interface, (2) incorporation of $\mathrm{V}$ into the passive film, and (3) deposition of $\mathrm{V}$ on the iron-containing cathodic particles and therefore, retardation of cathodic reaction.

npj Materials Degradation (2022)6:15; https://doi.org/10.1038/s41529-022-00225-5

\section{INTRODUCTION}

Global warming and climate change are some of the ongoing severe concerns that the world is facing. The research to reduce fossil fuel consumption via enhancing the fuel efficiency of the vehicles, increasing service life, and reducing material consumption has attracted significant research attention. Therefore, the development of high-strength, lightweight, corrosion-resistant alloys became crucial to meet current technological and environmental challenges. Among most metallic materials in practice, $\mathrm{Al}$ alloys exhibit an outstanding strength-to-weight ratio ${ }^{1}$. However, commercially available Al alloys exhibit a tradeoff between mechanical and corrosion properties, limiting their application in many industries. Corrosion and mechanical properties of Al alloys can be controlled by appropriate processing routes along with suitable composition. For example, nanocrystalline Al alloys produced by non-conventional techniques such as sputter deposition $^{2-4}$ and ion implantation ${ }^{5,6}$ were supersaturated solid solution and exhibited high corrosion resistance.

High-energy ball milling (HEBM), also known as mechanical, alloying is reported to cause amorphization, grain refinements, formation of non-equilibrium phases, and uniform dispersion of immiscible elements, which impart unique properties including simultaneous improvement of corrosion and mechanical properties $^{7-11}$. For instance, Esquivel et al. reported that high-energy ballmilled alloys of $\mathrm{Al}$ with corrosion-resistant alloying elements (V) resulted in high strength and corrosion resistance-higher than any commercial alloys ${ }^{9}$. The microstructure of the ball-milled alloys contained fine intermetallics and matrix with high solid solubility of the alloying elements where solid solubility was several orders higher than that predicted by the phase diagrams. The corrosion resistance of the ball-milled Al alloys was high despite a nonuniform microstructure. The improved corrosion resistance of these Al alloys was hypothesized due to one or more of the following mechanisms, which are proposed based on the literature on the sputter-deposited Al alloys, ball-milled alloys Al, and stainless steels $s^{4,12-14}$.
1. Enrichment of the passive film with the alloying elements improved passivity and decreased passive film breakdown. The proposed mechanism is motivated by the phenomenon causing stainless behavior in $\mathrm{Fe}-\mathrm{Cr}$ alloys by selective dissolution of $\mathrm{Fe}$ and enrichment of $\mathrm{Cr}$ in the form of $\mathrm{Cr}_{2} \mathrm{O}_{3}$.

2. Increased repassivation abilities of the alloys by:

(a) Prevention of the formation of critical pit solution by lower dissolution rates in the pits and lower hydrolysis of the ions

(b) Enrichment of the corroding alloy/electrolyte interphase with a corrosion-resistant alloying element

(c) Redeposition of the solute ions on the cathodic particles (such as Fe containing intermetallics) and decrease the cathodic reaction

3. Release of the oxyanions (i.e., molybdate and vanadate) can inhibit corrosion in initiation stages and accelerate the repassivation.

4. Doping of the passive film with solute ions and therefore increased vacancy annihilation.

Experimental or theoretical verification of the aforementioned mechanisms has not been presented in the literature, mainly because of the unavailability of suitable test specimens and limited resolution of analytical techniques used to study the surface film. The samples produced by the cold compaction of ball-milled powder exhibits significant porosity ${ }^{15}$. Most of the techniques to produce fully consolidated alloys need exposure to high temperatures, which decomposes the supersaturated solid solution to the thermodynamically stable phases ${ }^{16}$. The complex microstructure imposes challenges in developing a mechanistic understanding of corrosion. Therefore, a technique able to produce fully consolidated ball-milled alloys without exposure to high temperatures is desirable to study the ball-milled alloys and their properties.

High-energy ball milling performed under certain specific conditions has been reported to result in fully consolidated samples in the form of coarse particles, discs, or spheres

\footnotetext{
${ }^{1}$ Department of Materials Science and Engineering, North Carolina State University, Raleigh, NC 27695, USA. ${ }^{凶}$ email: rkgupta2@ncsu.edu
} 
depending on the material. Such formation of larger particles is termed in situ consolidation (ISC), which has been reported for only a few materials, e.g., $\mathrm{Zn}^{17,18}, \mathrm{Cu}^{19-21}, \mathrm{Fe}-\mathrm{Cr}-\mathrm{Ni}^{22}, \mathrm{Al}-\mathrm{Pb}-\mathrm{W}^{23}$, and $\mathrm{Al}-\mathrm{Cr}^{8}$. Synthesizing in situ consolidated nanocrystalline $\mathrm{Al}$ alloys and studying their properties is beneficial in studying the microstructure and the corrosion mechanisms of ball-milled alloys.

The influences of microstructural features on localized corrosion and the passive film characteristics of high-energy ball-milled Al-V alloys have been investigated herein. The validity of the abovementioned proposed mechanisms (1-4) has been tested using various electrochemical and characterization techniques. The role of secondary phases in localized corrosion and the influence of the solute on the passive film characteristics, corrosion initiation, and propagation mechanism have been discussed.

\section{RESULTS}

\section{Scanning electron microscopic (SEM) and scanning transmission electron microscopic (STEM) analysis}

In situ consolidated (ISC) disks of Al-2 at.\%V alloy (ISC-AI2V) are shown in Fig. 1a. The diameter of the disks varied from 1 to $5 \mathrm{~mm}$, and thickness was typically $0.5 \mathrm{~mm}$. Backscatter electron (BSE) images and energy-dispersive X-ray spectroscopy (EDXS) analysis showed uniform dispersion of $\mathrm{V}$ in $\mathrm{Al}$ (Supplementary Fig. 1). Ferich particles (Fig. 1b), attributed to the abrasion of milling media during the HEBM process, are confirmed by EDXS analysis (Supplementary Fig. 1). The STEM images of the ISC-AI2V alloy are shown in Fig. 1c, d along with the selected area diffraction (SAD) pattern (Fig. 1e), which reveals a nanocrystalline structure and formation of a supersaturated solid solution of Al-V. The inter planer distance of (111) plane obtained from the SAD pattern was used to determine the lattice parameter $(4.042546 \AA)$, which is smaller than that of pure $\mathrm{Al}(4.04958 \AA)$. Contraction in the lattice can be attributed to the incorporation of $\mathrm{V}$ as a solid solution. The solid solubility of the $\mathrm{V}$ was estimated to be $\sim 0.89$ at.\% using the lattice parameters and Vegard's law ${ }^{24}$. The estimated solid solubility of $\mathrm{V}$ in $\mathrm{Al}$ is $\sim 10^{5}$ times higher than the solubility predicted by the equilibrium phase diagram at room temperature $^{25}$. The high angle annular dark-field (HAADF) images (Fig. 1c, d) revealed the distribution of the V-rich phase and the elongated grains. High magnification HAADF images were used to estimate the grain size (diagonal) and presented in Fig. 1f, which shows a wide variation in the grain size. A small fraction of grains was coarse as 0.5 microns, whereas most grains were $<100 \mathrm{~nm}$. STEM analysis revealed homogeneously distributed phases rich in $\mathrm{V}$ and appearing bright in Fig. 1c, d.

\section{X-ray diffraction (XRD) analysis}

X-ray diffraction scans for the ISC-AI2V alloy and pure Al are shown in Fig. 1g, which showed peaks corresponding to $\mathrm{FCC} \mathrm{Al}$ and $\mathrm{Al}_{3} \mathrm{~V}$. Peak broadening and decrease in peak intensity were observed in ISC-AI2V compared to pure Al. A peak corresponding to $\mathrm{Al}_{3} \mathrm{~V}$ intermetallic indicates that HEBM facilitates the formation of both supersaturated solid solution and intermetallic. A peak shift towards a higher $2 \theta$ value compared to pure Al was observed in the ISC-AI2V alloy (Supplementary Fig. 2) and was attributed to the reduction of the lattice parameter caused by the formation of the solid solution of $\mathrm{V}$ in Al. The solid solubility of $\mathrm{V}$ in $\mathrm{Al}$ was estimated using XRD analysis (0.92 at.\%), consistent with that value estimated from the transmission electron microscopic (TEM) analysis. The average grain size was calculated using peak broadening and was $\sim 45 \mathrm{~nm}$, which is close to the Lorentzian peak of the grain size determined by TEM (Fig. 1f). The formation of a nanocrystalline structure was revealed from both XRD and TEM analysis which agrees with the literature on enhancing grain refinement and formation on non-equilibrium microstructure by HEBM $^{15,26,27}$.

\section{Cyclic potentiodynamic polarization (CPP) test}

Typical cyclic potentiodynamic polarization curves for ISC-AI2V and pure $\mathrm{Al}$ after $30 \mathrm{~min}$ of open circuit potential (OCP) stabilization in $0.01 \mathrm{M} \mathrm{NaCl}$ are presented in Fig. 2a. The average corrosion potential $\left(\mathrm{E}_{\mathrm{corr}}\right)$, pitting potential $\left(\mathrm{E}_{\mathrm{pit}}\right)$, and corrosion current density ( $i_{\text {corr }}$ ) were derived from the CPP curve fitting and are presented in supplementary Table 1 . The average $\mathrm{i}_{\text {corr }}$ for pure $\mathrm{Al}$ in $0.01 \mathrm{M} \mathrm{NaCl}$ was $0.12 \mu \mathrm{A} / \mathrm{cm}^{2}$, which is $\sim 2$ times higher than that in ISC-AI2V alloy. The $\mathrm{E}_{\text {pit }}$ of ISC-AI2V was $479 \mathrm{mV}_{\mathrm{SCE}}$ higher than that in pure $\mathrm{Al}$ ( $99.99 \%$ purity). The higher corrosion resistance of ISC-AI2V alloy, as evident from higher $\mathrm{E}_{\mathrm{pit}}$ and lower $i_{\text {corr }}$ could be attributed to the uniform dispersion of $\mathrm{V}$ in $\mathrm{Al}$, extended solid solution of $\mathrm{V}$ in $\mathrm{Al}$, and nanocrystalline structure $8,10,11$.

The formation of critical pit solution (CPS) due to the hydrolysis of the cations within the pit and migration of $\mathrm{Cl}^{-}$ from the electrolyte is necessary for the pit growth, and any conditions ceasing the CPS formation would cause repassivation. The addition of V in ISC-AI2 V may decrease the dissolution of the alloy to the level that a critical pit solution is not formed ${ }^{2}$. The addition of $\mathrm{V}$ may also increase the stability of the passive film at lower $\mathrm{pH}$, which could cause repassivation inside the pits $^{13}$. To comprehend this phenomenon about the influence of $\mathrm{V}, \mathrm{CPP}$ was performed in $0.1 \mathrm{M} \mathrm{HCl}$ (Supplementary Fig. 3), which showed considerably lower corrosion current density and anodic current density in ISC-AI2V, confirming obstacles in the formation of CPS.

\section{Electrochemical impedance spectroscopy (EIS) analysis}

Electrochemical impedance spectroscopy measures the passive film resistance and ionic transportation through the passive film. EIS measurements were performed for 14 days at regular time intervals. The Nyquist plots for both ISC-AI2V and pure Al are shown in Fig. 2b. Both ISC-AI2V and pure Al are characterized by two-time constants, one at high frequencies and the second at low frequencies. These two-time constants correspond to the passive film and localized corrosion, respectively ${ }^{28,29}$. The experimental data fitting was carried out using Zview software and the equivalent circuit shown in Fig. $2 \mathrm{c}$, where, $R_{S}$ is the solution resistance, $C P E_{\text {film }}$ and $R_{\text {film }}$ represent the film constant phase element and the resistance of the film, respectively, $C P E_{d l}$ and $R_{c t}$ denote the double layer constant phase element and charge transfer resistance, respectively. A constant phase element represents a deviation from an ideal capacitor.

Both ISC-AI2V and pure Al revealed a continuous increment of the total impedance (|Z|) over the immersion time (Fig. 2b). The $R_{\text {film }}$ and $R_{c t}$ of ISC-Al2V after $12 \mathrm{~h}$ of immersion were much higher than that in pure $\mathrm{Al}$, indicating higher corrosion resistance in ISC$\mathrm{Al} 2 \mathrm{~V}$ than that in pure Al. Both ISC-AI2V and pure Al showed $R_{\text {film }}$ increment over the immersion time (Supplementary Table 2). $R_{\text {film }}$ for pure Al and ISC-AI2V was almost similar after $336 \mathrm{~h}$ of immersion. Nevertheless, ISC-AI2V displayed a significant increment of $R_{c t}$ over the immersion time until $336 \mathrm{~h}$. The improved $R_{c t}$ in ISC-AI2V could be attributed to the formation of corrosion products inside the pit that can partially block the formed pits, which could act as a barrier for ion transportation between electrolyte and substrate ${ }^{30}$, whereas the $R_{c t}$ after $12 \mathrm{~h}$ of immersion of pure Al dropped noticeably after $48 \mathrm{~h}$ and increased gradually over the immersion time until $336 \mathrm{~h}$. The $C P E_{\text {film }}$ and $C P E_{d l}$ were noticeably lower for ISC-AI2V compared to that in pure Al. In ISC-AI2V, the CPE film was increased until $96 \mathrm{~h}$ and gradually declined with the continuous immersion, probably due to the passive film growth rather than the influence of hydration. The $C P E_{d l}$ for ISC-Al2V dropped from 12 to $96 \mathrm{~h}$ followed by gradual increment, whereas in pure $\mathrm{Al}, C P E_{\text {film }}$ and $C P E_{d l}$ increased over the immersion time. The corrosion resistance improvement of ISC$\mathrm{Al} 2 \mathrm{~V}$ in the long-term EIS tests is attributed to the enhancement of 

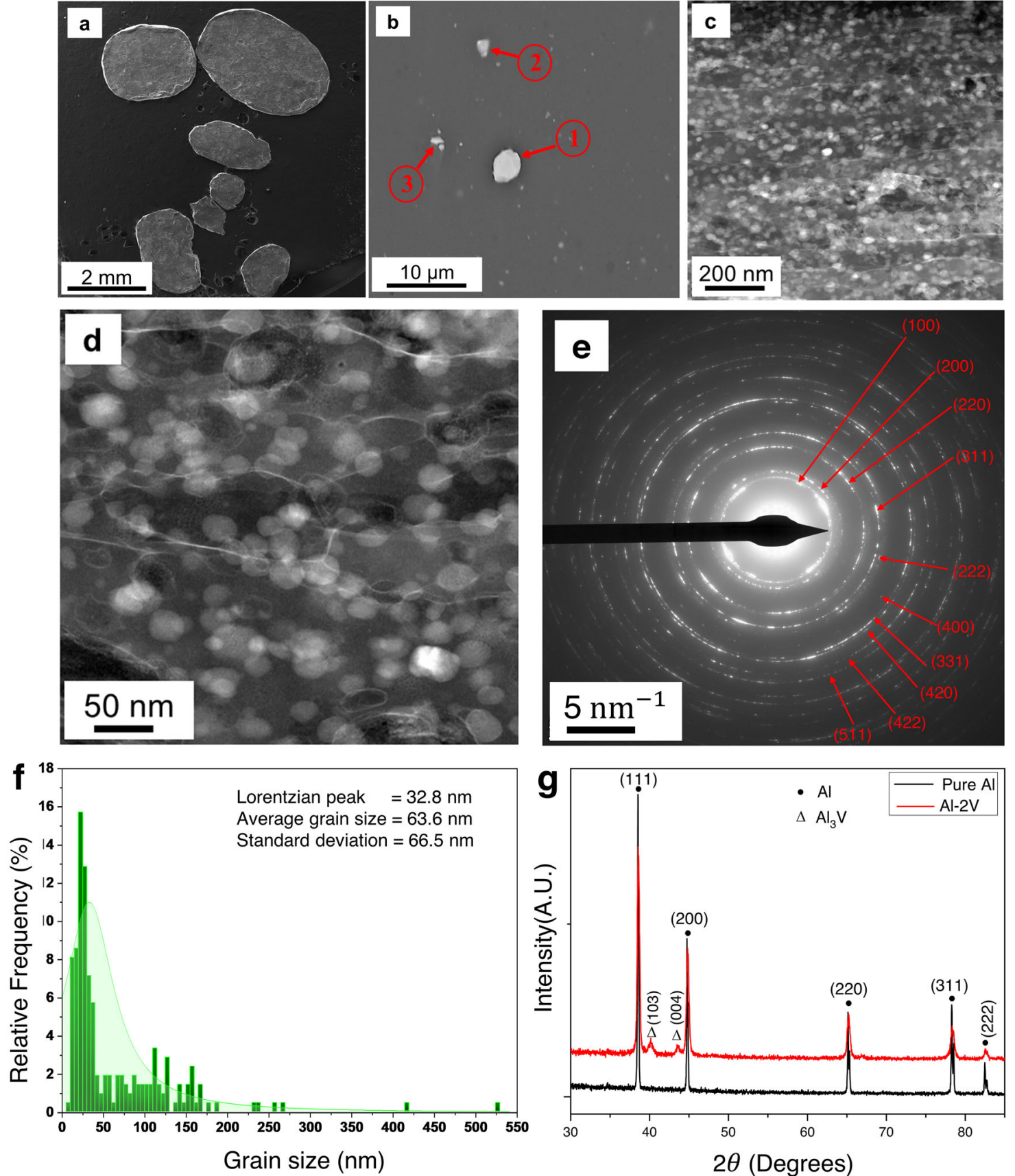

Fig. 1 Microstructural characterization of ISC-AI2V alloy. a BSE image of the whole samples, $\mathbf{b}$ zoomed-in region showing the Fe rich particles marked by the arrows, $\mathbf{c}$ HAADF STEM revealing the distribution of V-rich phase, $\mathbf{d}$ HAADF image illustrating the grain size, e SAD pattern, $\mathbf{f}$ grain size distribution estimated from the SAD pattern shown in (e), $\mathbf{g}$ XRD scans of ISC-Al2V alloy comparison with pure aluminum.

both $R_{\text {film }}$ and $R_{c t}$ compared to that in pure Al. However, $R_{c t}$ enhancement in the alloy is significantly higher that $R_{\text {film }}$ increment, which could be suggested to the enhancement of the pitting corrosion resistance with an increase in the immersion time. An increase in pitting corrosion resistance could occur because of (1) change in the surface of the alloy within the pits, i.e., enrichment of the $V$ near electrolyte/alloy interface within the pit, (2) repassivation due to decreased cathodic activities of cathodic sites (initiation sites for pitting), (3) inability to form CPS and therefore repassivation. These factors are discussed in the following sections.

\section{Defect concentration in the passive film using Mott-Schottky analysis}

Mott-Schottky analysis of ISC-AI2V and pure Al after immersion in $0.01 \mathrm{M} \mathrm{NaCl}$ for $30 \mathrm{~min}$ was performed (Fig. 2d) to evaluate the passive film and understand the presence of point defects. A positive slope was noticed in both ISC-AI2V, and pure Al, which revealed that the formed passive films are n-type semiconductors. It has been widely accepted that the donors such as oxygen vacancies and cation interstitials are the dominant charge carriers in n-type passive films $\mathrm{s}^{31,32}$. The average donor density of ISC-AI2V was $\sim(1.906 \pm 0.32) \times 10^{18} \mathrm{~cm}^{-3}$ which is $\sim 1.66$ times lower than 

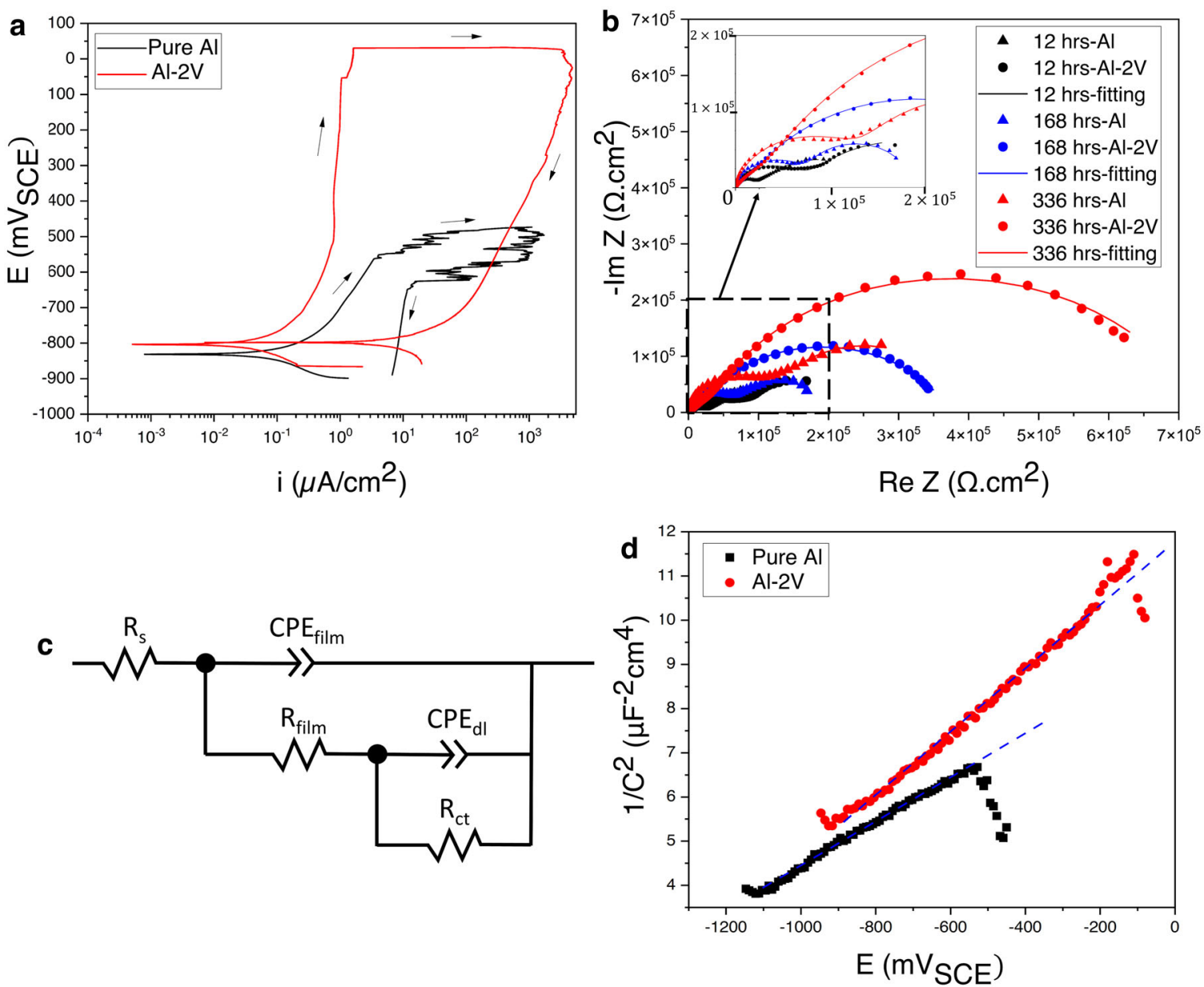

Fig. 2 Electrochemical behavior of ISC-AI2V alloy in comparison with pure Al in $\mathbf{0 . 0 1} \mathbf{~ M ~ N a C l}$. a Representative CPP curves after 30 min of OCP stabilization, b Nyquist curves at OCP for various immersion times, $\mathbf{c}$ the equivalent circuit diagram used for EIS data fitting for both ISC$\mathrm{Al} 2 \mathrm{~V}$ and pure $\mathrm{Al}$, d Mott-Schottky curves with trend lines (blue dotted) after $30 \mathrm{~min}$ of stabilization.

that in pure Al. A lower density signifies higher corrosion resistance.

\section{X-ray photoelectron spectroscopy (XPS) and secondary ions mass spectrometry (SIMS)}

The X-ray photoelectron spectroscopy and time-of-flight secondary ions mass spectrometry analysis were performed on ISC-AI2 V after polishing and immersion in $0.1 \mathrm{M} \mathrm{NaCl}$ solution for $0 \mathrm{~min}$, $5 \mathrm{~min}, 30 \mathrm{~min}$, and 2 days. XPS survey scans detected $\mathrm{Al}, \mathrm{O}$, and $\mathrm{V}$. Supplementary Fig. 4 shows the survey scans, and the elemental distribution is presented in supplementary Table 3. Highresolution regional scans of $\mathrm{O}, \mathrm{Al}$, and $\mathrm{V}$ are presented in Fig. 3. The $\mathrm{O} 1 \mathrm{~s}$ peak was deconvoluted into two peaks named as $\mathrm{O} 1 \mathrm{~S}_{\mathrm{A}}$ and $\mathrm{O} 1 \mathrm{~S}_{\mathrm{B}}$. The $\mathrm{O} 1 \mathrm{~S}_{\mathrm{A}}$ peak at lower binding energy $(\sim 532.5 \mathrm{eV})$ was attributed to the oxide contribution, and the $O 1 \mathrm{~S}_{B}$ peak at higher binding energy $(\sim 533.7 \mathrm{eV})$ was associated with the hydroxide and/or oxygen bonded carbon contamination. Figure $3 \mathrm{~b}$ represents $\mathrm{Al} 2 \mathrm{p}$ peak with two binding energies: A peak with lower binding energy at $\sim 72.9 \mathrm{eV}$ corresponded to metallic Al and the higher binding energy ( 75.6 eV) associated with Al oxide/ hydroxide peak ${ }^{33}$. Each Al peak was further deconvoluted into two peaks: The metallic Al peak deconvoluted into $2 p_{3 / 2}(\sim 72.8 \mathrm{eV})$ and $2 p_{1 / 2}(\sim 73.2 \mathrm{eV}) . \mathrm{An} \mathrm{Al}_{2} \mathrm{O}_{3}$ peak at $\sim 75.3 \mathrm{eV}$ and $\mathrm{Al}(\mathrm{OH})_{3}$ peak at $\sim 75.9 \mathrm{eV}$ were obtained from the deconvolution of the oxide/ hydroxide peak. The intensity of the Al oxide/hydroxide peak increased with the immersion time, whereas the intensity of the metallic peak decreased over the immersion time; it could be attributed to the film growth on the surface. Due to a thick surface layer, the metallic Al peak was not detected after 2 days of immersion. The film thickness, calculated using the method reported in the literature ${ }^{34,35}$, was $2.97,3.02$, and $4.95 \mathrm{~nm}$ for 0,5 , and $30 \mathrm{~min}$ of immersion time, respectively. The $\mathrm{O} / \mathrm{Al}$ atomic ratio was estimated from $\mathrm{O} 1 \mathrm{~s}$ and $\mathrm{Al} 2 p$ air-formed peaks (Supplementary Table 3 ). The estimated O/Al atomic ratio was 2.43 , more significant than the stoichiometric value of 1.5 (i.e., $\mathrm{Al}_{2} \mathrm{O}_{3}$ ), attributed to hydroxide formation. The $\mathrm{O} / \mathrm{Al}$ ratio was increased over the immersion time and reached 3.10, which is closer to the $\mathrm{O} / \mathrm{Al}$ ratio in $\mathrm{Al}(\mathrm{OH})_{3}$. The continuous hydration of the oxide layer and formation of an external $\mathrm{Al}(\mathrm{OH})_{3}$ could be attributed to the increase in the O/Al ratio with immersion time. Moreover, oxides or hydroxides of $\mathrm{V}$ also contribute to the overall oxygen content of the passive film. Figure $3 c$ shows the experimental V $2 p$ peak and the four deconvoluted peaks representing four different oxidation states of $\mathrm{V}$ (i.e., $\mathrm{V}^{0+}, \mathrm{V}^{3+}, \mathrm{V}^{4+}$, and $\mathrm{V}^{5+}$ ). The intensity of the metallic $V$ peak was highest in air-formed and gradually decreased over the immersion time. The $\mathrm{V}^{4+}$ content was the highest among all the oxidized $V$ in all the four immersion conditions, followed by $\mathrm{V}^{3+}$ and then $\mathrm{V}^{5+}$. A gradual decrease in $\mathrm{V}^{5+}$ content was noticed over the immersion time.

The secondary ion mass spectrometry (SIMS) analysis for ISC$\mathrm{Al} 2 \mathrm{~V}$ shows depth profiles for ${ }^{18} \mathrm{O}^{-}, \mathrm{OH}^{-}, \mathrm{Al}_{2}^{-}, \mathrm{AlO}_{2}^{-}, \mathrm{VO}^{-}$, and $\mathrm{V}^{-}$. The ions $\mathrm{Al}_{2}{ }^{-}$(53.9636 amu) and $\mathrm{AlO}_{2}{ }^{-}$(58.9719 amu) corresponds to metallic $\mathrm{Al}$ and $\mathrm{Al}$ oxide, respectively ${ }^{36,37}$. The oxygen characteristic for the oxide scale is presented by the ${ }^{18} \mathrm{O}^{-}$ (17.9997 amu) since the ${ }^{16} \mathrm{O}^{-}(15.9955 \mathrm{amu})$ saturates the 

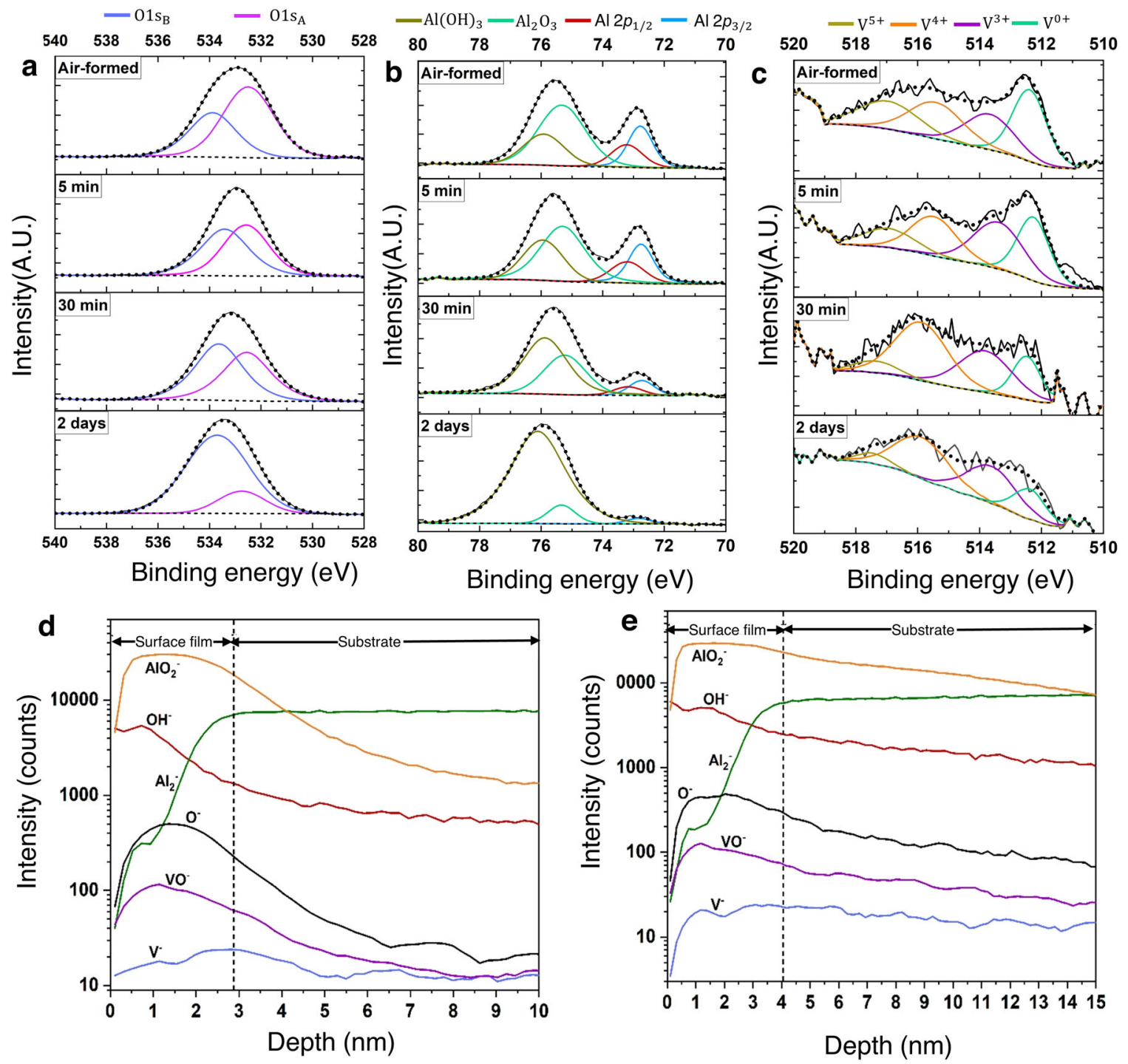

Fig. 3 Surface film characterization of ISC-AI2V. a-c XPS regional scan of O $1 s, \mathrm{Al} 2 p$, and $\mathrm{V} 2 p_{3 / 2}$ peaks following immersion in $0.1 \mathrm{M}$ NaCl for various times. The spectra are shown in thin solid lines, envelope in dotted lines, and background in dashed lines. $\mathbf{d}$, e ToF-SIMS negative ion depth profiles of ISC-AI2V for air-formed and $30 \mathrm{~min}$ of immersion in $0.1 \mathrm{M} \mathrm{NaCl}$ solution, respectively.

detector. The metallic and oxidized $\mathrm{V}$ is shown by $\mathrm{V}^{-}$ (50.9445 amu) and $\mathrm{VO}^{-}$(66.9394 amu). Two regions were defined as surface film and the metallic substrate, separated by the dotted lines (Fig. 3d, e). Moreover, the metallic substrate begins once the $\mathrm{Al}_{2}{ }^{-}$curve reaches the plateau. The surface film thickness was $\sim 2.88,3.10,4.06$, and $35.63 \mathrm{~nm}$ for $0 \mathrm{~min}, 5 \mathrm{~min}, 30 \mathrm{~min}$, and 2 days of immersion. ${ }^{18} \mathrm{O}^{-}, \mathrm{OH}^{-}, \mathrm{AlO}_{2}^{-}, \mathrm{V}^{-}$, and $\mathrm{VO}^{-}$were observed in the surface film in all four conditions exhibit the presence of both metallic and oxidized $\mathrm{V}$ in the passive film. A slight increment of $\mathrm{V}^{-}$ions was observed at the substrate/surface film interface in both air-formed and 5 min (Supplementary Fig. 5a); immersed samples exhibit the enrichment of metallic $\mathrm{V}$ at the substrate/ surface film. This metallic $V$ enrichment at the substrate/surface film interface may be a barrier to the further dissolution/oxidation of the aluminum ${ }^{13}$. After 2 days of immersion, the $V$ enriched layer was shifted towards the surface film/electrolyte interface (Supplementary Fig. 5b). The $\mathrm{VO}^{-}$ion enrichment was observed near the middle of the surface film in all four conditions. This incorporation of $\mathrm{V}$ in the passive film and development of $\mathrm{V}$ enriched layer is expected to contribute to observed enhancement in corrosion resistance.

\section{Characterization of the passive film and pits using STEM}

STEM cross-section images of the passive film and pit for ISC-AI2V alloy after $30 \mathrm{~min}$ of immersion in $0.1 \mathrm{M} \mathrm{NaCl}$ are shown in Figs. 4 and 5. Figure 4a shows the formation of a uniform passive film with an average thickness of $5.6 \mathrm{~nm}$, consistent with the passive film thickness estimated from XPS and SIMS. The EDXS elemental mapping was performed on the region in Fig. 4b (HAADF), revealing $\mathrm{Al}, \mathrm{O}$, and $\mathrm{V}$ (Fig. $4 \mathrm{c}-\mathrm{f}$ ). The $\mathrm{O}$ was distributed on the top of the alloy surface, confirming a uniform passive film (Fig. 4e). Figure $4 \mathrm{f}$ shows the enrichment of $\mathrm{V}$ underneath the passive film, which agrees with the enrichment of $V$ observed at the surface film/substrate interface through SIMS analysis. The V content was estimated using an EDXS line scan along with the red arrow (Fig. 4f). The highest $V$ content was observed underneath the passive film (Fig. 4g).

A cross-sectional image of a pit developed after immersion in $0.1 \mathrm{M} \mathrm{NaCl}$ for $30 \mathrm{~min}$ is presented in Fig. $5 \mathrm{a}$. The pit growth was insignificant even after 2 days of immersion (Supplementary Fig. 6). The EDXS analysis was performed on the magnified crosssectional image of the pit (Fig. 5b-f), confirming the presence of Fe-rich particles inside the pit. Fe containing intermetallics are cathodic and initiate corrosion in $\mathrm{Al}^{38}$. V was observed on the Fe- 

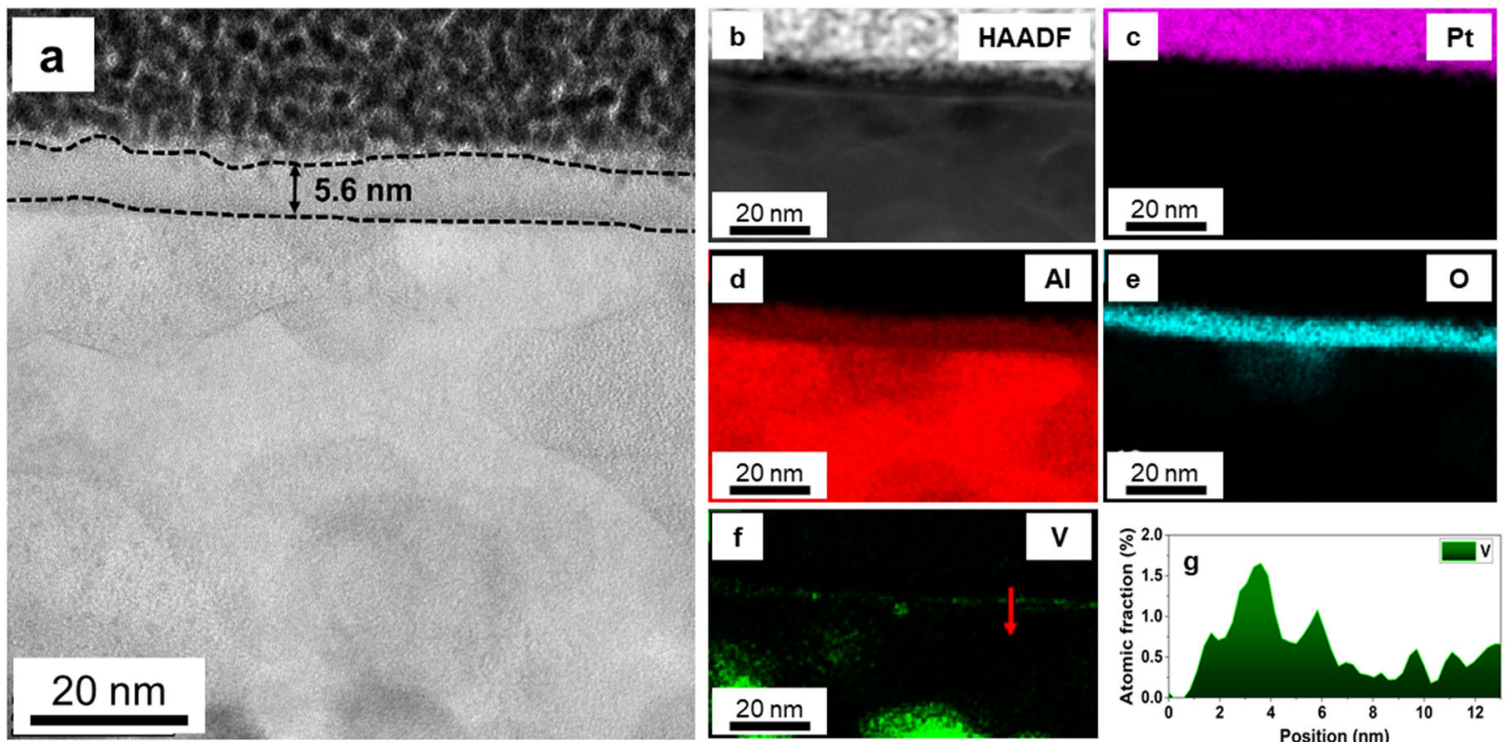

Fig. 4 Structure of the passive film of ISC-AI2V alloy. a STEM image showing the uniform passive film, $\mathbf{b}$ zoomed-in HAADF STEM image, $\mathbf{c}-\mathbf{f}$ EDXS elemental mapping of the same region in (b) and, $\mathbf{g}$ distribution of $V$ along the red arrow in (f) revealing the $V$ enrichment at the oxide/ metal interface.

rich particles (Fig. 5f), indicating the $\mathrm{V}$ deposition during corrosion inside the pit and, therefore, decreased cathodic activity of Fe-rich pitting and repassivation in the early stages of pitting corrosion. The corrosion inhibition mechanism of $\mathrm{V}$ could be analogs corrosion inhibition of vanadate corrosion inhibitor ${ }^{39,40}$. In addition, enrichment of $\mathrm{V}$ under the corrosion product layer and within the corrosion products in the pit is observed (Fig. 5f). The net intensity of $\mathrm{V}$ was estimated along with the red arrow indicated in Fig. 5f. The $\mathrm{V}$ content underneath the pit was slightly higher than that in the matrix region (Fig. 5g), revealing $\mathrm{V}$ enrichment underneath the pit. The observed phenomenon of $\mathrm{V}$ deposition on the Fe-rich particles and incorporation of $\mathrm{V}$ in corrosion produced within the pits is confirmed by the TEM study of ISC-AI2V alloy after 2 days of immersion (Supplementary Fig. 6). The size of the pits after 30 min and 2 days of immersion was almost similar, indicating inhibition of the corrosion in the early stages of initiation.

\section{DISCUSSION}

Both XPS and SIMS revealed the incorporation of metallic and oxidized $V$ into the passive film developed on ISC-AI2V. This oxidized $V$ species (i.e., $\left.V^{n+}(n=3,4,5)\right)$ in the passive film of ISC$\mathrm{Al} 2 \mathrm{~V}$ could interact with oxygen vacancies. Therefore, the number of oxygen vacancies decreased compared to the pure Al, as observed in the Mott-Schottky analysis (Fig. 2d). The doping of solute $\mathrm{V}$ with oxygen vacancies present in the passive film could be attributed to the formation of complex species that have neutral and null mobility. Chloride was not detected by the SIMS and XPS. It should be noted that the incorporation of $\mathrm{Cl}$ to the passive film is attributed to the localized corrosion of $\mathrm{Al}^{41,42}$. The absence of chloride shows the effectiveness of $\mathrm{V}$ in preventing $\mathrm{Cl}$ incorporation to the passive film and therefore improving pitting corrosion resistance.

The enrichment of the V-rich layer underneath the passive film was observed by both TEM and SIMS. Moreover, Supplementary Fig. 7 revealed that V-rich phase became a part of the passive film instead of the dissolution during passive film formation. The observed enrichment of $\mathrm{V}$ underneath passive film is attributed to higher dissolution kinetics of $\mathrm{Al}$ than $\mathrm{V}$. The incorporation of both metallic and oxidized $\mathrm{V}$ in the passive film and the enrichment of
$\mathrm{V}$ underneath the film enhances the passive film stability. Consequently, the passive film resistance (EIS analysis), pitting potential, and the passive window (in the CPP curve) increase in ISC-AI2V compared to pure Al.

The schematic representation of pit initiation and repassivation in the early stages of pitting corrosion is shown schematically in Fig. 6 . The pitting corrosion in ISC-AI2V initiates at the interface of Fe-rich particles and matrix. Fe-rich particles are reported to be cathodic in nature ${ }^{38}$, i.e., act as a site for the cathodic reaction (i.e., oxygen reduction reaction), and introduce an alkaline environment around them and localized dissolution of the passive film ${ }^{43}$. Subsequently, the interaction between the alloy substrate and the electrolyte caused the rapid oxidation of Al that led to the pit initiation (Fig. 6a). The hydrolysis of the metal cations causes localized acidification within the pit, and chloride ion transportation occurs toward the pit to maintain the charge neutrality inside the pit ${ }^{44}$. The enriched $\mathrm{V}$ layer underneath the pit (Fig. 6b) has two effects (1) low dissolution rate (Supplementary Fig. 3) and therefore inability to sustain a critical pit solution necessary for pit growth and (2) release of oxidized vanadium species (vanadates), which are well-known corrosion inhibitors ${ }^{39,40}$. The disposition of V (Figs. 5 and $6 \mathrm{~b}$ ) on Fe-rich particles is attributed to the decrement in the cathodic efficiency of the Fe-rich particles and eventually repassivation of the pit at very early stages of corrosion. The deposition of $\mathrm{V}$ on Fe-rich particles is a significant finding and indicates that uniform dispersion of the alloying elements that can form corrosion inhibitors could potentially cause repassivation at the early stage of corrosion.

In summary, ISC-AI2V alloy exhibited enhancement of corrosion resistance, significantly higher than pure Al. A combination of electrochemical and analytical techniques provided an understanding of the corrosion mechanisms. The improved corrosion resistance of ISC-AI2V alloy is attributed to inhibition of pitting corrosion by the disposition $\mathrm{V}$ on the cathodic iron-containing particle, the enhancement of passive film stability due to the incorporation of $\mathrm{V}$ species in the passive film, and the enrichment of $V$ at the passive film/substrate interface. Mechanisms for the improved corrosion resistance presented herein are expected to facilitate the determination of corrosion-resistant microstructures, selection of alloying elements, choice of manufacturing 

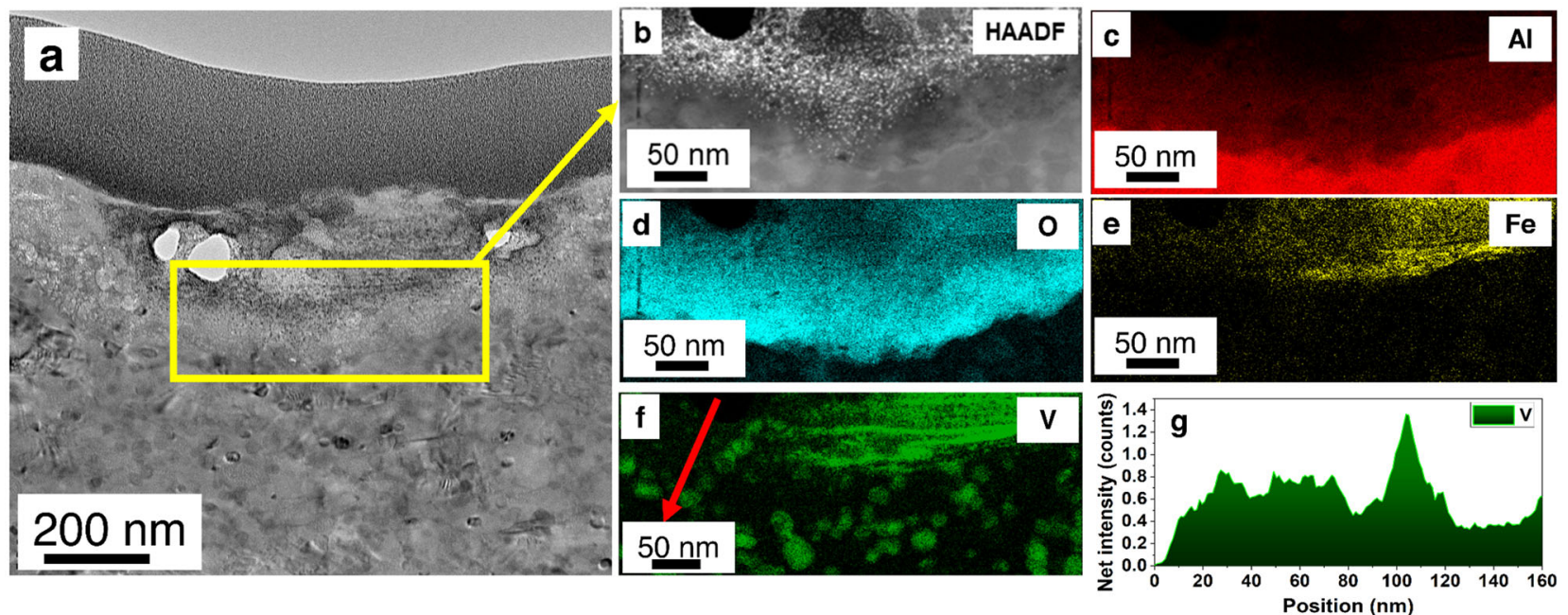

Fig. 5 Pit morphology of ISC-AI2V alloy. a STEM cross-section sample prepared by FIB revealing the pit morphology after 30 min of immersion in $0.1 \mathrm{M} \mathrm{NaCl}$, $\mathbf{b}$ zoomed-in HAADF image, $\mathbf{c}-\mathbf{f}$ EDXS elemental mapping of the region in (b)), and $\mathbf{g}$ distribution of $\mathrm{V}$ along the red arrow in (f) revealing the $\mathrm{V}$ enrichment underneath pit.

a

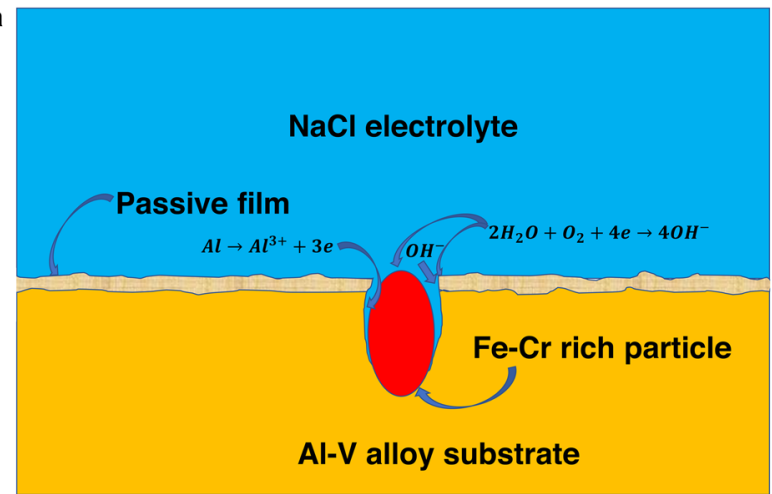

b

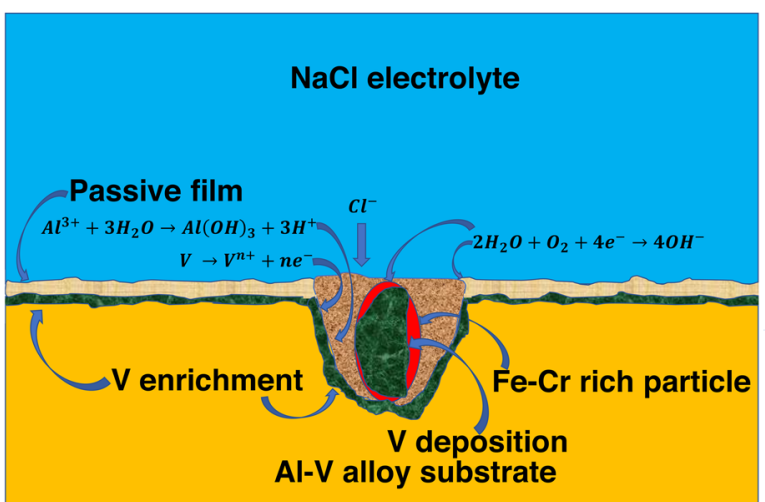

Fig. 6 Schematic representation of the proposed corrosion and inhibition mechanisms. a Localized corrosion initiation around the $\mathrm{Fe}-\mathrm{Cr}$ rich particle and $\mathbf{b}$ corrosion inhibition due to the deposition of $\mathrm{V}$ on $\mathrm{Fe}-\mathrm{Cr}$ particle and enrichment of $\mathrm{V}$ under the passive film.

technologies for desired microstructure, and therefore facilitate the development of high strength and corrosion-resistant $\mathrm{Al}$ alloys.

\section{METHODS}

\section{Alloy synthesis}

ISC-AI2V alloy was produced using the Fritsch P-5/4 planetary ball mill. aluminum powder (purity $99.7 \%$ with $0.09 \%$ of iron, and $0.03 \%$ of silicon and mesh size $-50 /+100$ ) and vanadium powder (purity $99.8 \%$ and mesh size 325) were weighted inside the glove box with a high purity argon environment (oxygen $<25 \mathrm{ppm}$ ). The steel balls with $10 \mathrm{~mm}$ diameter were loaded into the jar. The ball-to-powder weight ratio was kept at 16:1. The weighted alloy powders (aluminum and vanadium) with the process controlling agent (1.5 wt\% Stearic acid) were filled into the jar and sealed inside the glove box. High-energy ball milling was performed at 350 RPM for $100 \mathrm{~h}$. The milling was paused for $30 \mathrm{~min}$ after each $1 \mathrm{~h}$ of milling to avoid overheating.

\section{Characterization}

Scanning electron microscopy and energy-dispersive X-ray spectroscopy. The SEM was performed using a field emission scanning microscope $\mathrm{FEI}$ Verios $460 \mathrm{~L}$ at $20 \mathrm{kV}$ accelerating voltage. The sample was grounded up to 1200 grit using SiC papers. The fine polishing up to $0.05 \mu \mathrm{m}$ was carried out using colloidal silica suspension followed by ultrasonication in ethanol for 10 min BSE images and EDXS elemental mapping for $\mathrm{Al}, \mathrm{V}, \mathrm{Fe}$, and $\mathrm{O}$ were performed on the sample to understand the microstructure and the elemental distribution.

\section{Scanning transmission electron microscopy}

The electron microscopy and spectroscopic analysis were conducted using a Thermo Scientific Titan aberration-corrected STEM operated at $200 \mathrm{kV}$. HAADF and bright-field (BF) images were obtained for ISC-AI2V alloy samples after $30 \mathrm{~min}$ and 2 days of immersion in $0.1 \mathrm{M} \mathrm{NaCl}$. The samples were polished up to $0.05 \mu \mathrm{m}$, followed by ultrasonic cleaning. The focused ion beam (FIB) technique was used to prepare the crosssectional TEM samples. An e-beam deposition of $300 \mathrm{~nm}$ Pt layer on the selected region followed by an ion beam deposition of $200 \mathrm{~nm}$ Pt layer on top was used to protect the surface during FIB. The EDXS elemental mapping was carried out to analyze the $\mathrm{Al}, \mathrm{V}, \mathrm{O}, \mathrm{Pt}$, and Fe distribution in each sample.

\section{X-ray diffraction}

XRD was performed using the Rigaku SmartLab X-ray diffractometer with a Cu Ka radiation $(\lambda=0.15406 \mathrm{~nm})$ filter. The XRD pattern was recorded in the $2 \theta$ range from 30 to $85^{\circ}$ with a step size of $0.02^{\circ}$ and a scanning rate $1^{\circ}$ per min. The average grain size was calculated using Scherrer's formula ${ }^{45,46}$ after subtracting instrumental broadening. The reported literature referred to the calculation of grain size and solid solubility $9,15,24,46$.

\section{X-ray photoelectron spectroscopy}

The passive film chemical composition of ISC-AI2V was studied in 0 min, $5 \mathrm{~min}, 30 \mathrm{~min}$, and 2 days of immersion in $0.1 \mathrm{M} \mathrm{NaCl}$ solution using SPECS XPS. The loose contamination was removed from the sample surface using DI water after the immersion test. The total vacuum 
chamber pressure was maintained below $10^{-9} \mathrm{mbar}$, and $\mathrm{Mg}$ anode was used as the X-ray source of $300 \mathrm{~W}$. The experiment was performed on the scan area of $2 \times 2 \mathrm{~mm}$ with a take-off angle of $60^{\circ}$. The survey scan was obtained from 0 to $1100 \mathrm{eV}$ binding energy to obtain the elements present on the surface. At the same time, high-resolution spectra were performed to identify the present elements in the passive film and their oxidation states. The binding energies were calibrated with the peak of $\mathrm{C} 1 \mathrm{~s}$ at $285.0 \mathrm{eV}$. High-resolution spectra of $1 \mathrm{~s}$ peak for $\mathrm{C}$ and $\mathrm{O}, 2 p$ peak for $\mathrm{Al}$ and $\mathrm{V}$ were recorded. The spectrum analysis was conducted using CASA software, considering background subtraction and relative sensitivity factors given by Scofield ${ }^{33}$.

\section{Secondary ions mass spectroscopy}

Elemental depth profiling was carried out for ISC-AI2V in $0 \mathrm{~min}, 5 \mathrm{~min}$, $30 \mathrm{~min}$, and 2 days immersion in $0.1 \mathrm{M} \mathrm{NaCl}$ solution using the time-offlight secondary ion mass spectroscopy (ToF-SIMS). The chamber pressure was maintained below $5 \times 10^{-9} \mathrm{mbar}$ in high mass resolution mode, and sputtering was performed using a $\mathrm{Cs}+$ ion beam with $1 \mathrm{keV}$ and $7.2 \mathrm{nA}$ target current over a $100 \times 100 \mu \mathrm{m}$ raster area. The target current was restored over an area of $20 \times 20 \mu \mathrm{m}$ using a Bi3+ primary ion source with $25 \mathrm{keV}$ and $0.32 \mathrm{pA}$. The negative ion profiles were recorded due to the higher sensitivity to fragments from the oxide region. The depth scale was calibrated using surface profilometry with the air-formed sample.

\section{Electrochemical measurements}

The specimens for corrosion testing were mounted in epoxy and grounded to 1200 grit SiC paper finish followed by ultrasonication in ethanol for $10 \mathrm{~min}$. The sample edges were sealed by epoxy resin (Araldite) and stored in a desiccator for about $12 \mathrm{~h}$ before testing (This method avoided crevice corrosion during the electrochemical test). A conventional three-electrode flat cell with the Pt mech counter electrode and saturated calomel reference electrode (SCE) was utilized for the experiment. Potentiodynamic polarization, EIS, and Mott-Schottky tests were performed using VMP-300 potentiostat (Biologic) with the help of the EC-lab software. All the electrochemical tests were repeated at least three times to ensure reproducibility.

\section{Potentiodynamic polarization}

ISC-AI2V and pure Al samples were immersed for $30 \mathrm{~min}$ in a $0.01 \mathrm{M} \mathrm{NaCl}$ for stabilization. The anodic polarization was performed separately with the sweep rate of $0.167 \mathrm{mV} / \mathrm{s}$ starting from $50 \mathrm{mV}_{\mathrm{SCE}}$ below the (OCP) toward the more positive potential direction. The scanning direction was reversed once the current reached $200 \mu \mathrm{A} / \mathrm{cm}^{2}$. The same procedure was followed with $0.1 \mathrm{M} \mathrm{HCl}$ instead of $0.01 \mathrm{M} \mathrm{NaCl}$ to understand the passive film stability at low $\mathrm{pH}$ conditions.

\section{Electrochemical impedance spectroscopy}

EIS measurements for the ISC-AI2V and pure Al were carried in a $0.01 \mathrm{M}$ $\mathrm{NaCl}$ solution using the $\mathrm{AC}$ sinusoidal voltage signal with $10 \mathrm{mV}$ amplitude and frequency range of $100 \mathrm{kHz}$ to $1 \mathrm{mHz}$. The EIS tests were performed over 14 days. The data was collected after every $12 \mathrm{~h}$.

\section{Mott-Schottky analysis}

The Mott-Schottky analysis was performed for both ISC-AI2V and pure Al. The sinusoidal voltage signal with $10 \mathrm{mV}$ amplitude and $1 \mathrm{kHz}$ frequency was used for both samples. The Mott-Schottky analysis was carried after 30 min of immersion in $0.01 \mathrm{M} \mathrm{NaCl}$. The scanning was done with 80 potential steps starting from $50 \mathrm{mV}_{\mathrm{SCE}}$ below OCP towards the more noble direction. At least three tests of measurements were carried out to ensure reproducibility.

\section{DATA AVAILABILITY}

The data that support the findings in this study is available upon a reasonable request.

Received: 1 November 2021; Accepted: 27 January 2022; Published online: 17 February 2022

\section{REFERENCES}

1. Dorward, R. C. \& Pritchett, T. R. Advanced aluminium alloys for aircraft and aerospace applications. Mater. Des. 9, 63-69 (1988).

2. Frankel, G. S., Newman, R. C., Jahnes, C. V. \& Russak, M. A. On the pitting resistance of sputter-deposited aluminum alloys. J. Electrochem. Soc. 140, 2192-2197 (1993).

3. Davis, G. D., Moshier, W. C., Fritz, T. L. \& Cote, G. O. Evolution of the chemistry of passive films of sputter-deposited, supersaturated Al alloys. J. Electrochem. Soc. 137, 422-427 (1990).

4. Metikoš-Hukovi, M., Radi, N., Grubač, Z. \& Tonejcv, H. A. The corrosion behavior of sputter-deposited aluminum-tungsten alloys. Electrochim. Acta 47, 2387-2397 (2002).

5. Natishan, P. M., McCafferty, E. \& Hubler, G. K. Localized corrosion behavior of aluminum surface alloys produced by ion implantation and ion beam mixing. Mater. Sci. Eng. A 116, 41-46 (1989).

6. Natishan, P. M., McCafferty, E. \& Hubler, G. K. The corrosion behavior of Mo-Al, Cr$\mathrm{Al}$ and $\mathrm{Cr}-\mathrm{Mo}-\mathrm{Al}$ surface alloys produced by ion beam mixing and ion implantation. Corros. Sci. 32, 721-731 (1991).

7. Gupta, R. K., Fabijanic, D. \& Dorin, T. Simultaneous improvement in the strength and corrosion resistance of $\mathrm{Al}$ via high-energy ball milling and $\mathrm{Cr}$ alloying. Mater. Des. 84, 270-276 (2015).

8. Gupta, R. K., Fabijanic, D., Zhang, R. \& Birbilis, N. Corrosion behaviour and hardness of in situ consolidated nanostructured $\mathrm{Al}$ and $\mathrm{Al}-\mathrm{Cr}$ alloys produced via highenergy ball milling. Corros. Sci. 98, 643-650 (2015).

9. Esquivel, J., Murdoch, H. A. \& Darling, K. A. Excellent corrosion resistance and hardness in Al alloys by extended solid solubility and nanocrystalline structure. Mater. Res. Lett. 6, 79-83 (2018).

10. Esteves, L. et al. Effect of $\mathrm{V}$ content on corrosion behavior of high-energy ball milled AA5083. Corros. Sci. 186, 109-465 (2021).

11. Esteves, L. et al. Corrosion behavior of AA5083 produced by high-energy ball milling. J. Alloy. Compd. 857, 158-268 (2021).

12. Esquivel, J. \& Gupta, R. K. Review-Corrosion-resistant metastable Al alloys: an overview of corrosion mechanisms. J. Electrochem. Soc. 167, 081504 (2020).

13. Davis, G. D., Shaw, B. A., Rees, B. J. \& Ferry, M. Mechanisms of passivity of nonequilibrium AI-W alloys. J. Electrochem. Soc. 140, 951-959 (1993).

14. Davis, G. D., Shaw, B. A., Rees, B. J. \& Pecile, C. A. Electrochemical behavior and surface chemistry of non-equilibrium aluminum-tantalum alloys: solute-rich interphase mechanisms. Surf. Interface Anal. 23, 609-617 (1995).

15. Esquivel, J. \& Gupta, R. K. Influence of the $V$ content on microstructure and hardness of high-energy ball milled nanocrystalline Al-V alloys. J. Alloy. Compd. 760, 63-70 (2018).

16. Xu, J., Collins, G. S., Peng, L. S. J. \& Atzmon, M. Deformation-assisted decomposition of unstable $\mathrm{Fe}_{50} \mathrm{Cu}_{50}$ solid solution during low-energy ball milling. Acta Mater. 47, 1241-1253 (1999).

17. Zhang, X., Wang, H., Scattergood, R. O., Narayan, J. \& Koch, C. C. Evolution of microstructure and mechanical properties of in situ consolidated bulk ultra-finegrained and nanocrystalline Zn prepared by ball milling. Mater. Sci. Eng. A 344, 175-181 (2003).

18. Zhang, X., Wang, H. \& Kassem, M. Preparation of bulk ultrafine-grained and nanostructured $\mathrm{Zn}, \mathrm{Al}$ and their alloys by in situ consolidation of powders during mechanical attrition. Scr. Mater. 46, 661-665 (2002).

19. Sikdar, K., Chakravarty, S. \& Roy, D. Synthesis and characterization of an in situ consolidated nanocrystalline $\mathrm{Cu}_{88} \mathrm{Al}_{11.5} \mathrm{Y}_{0.5}$ alloy. J. Alloy. Compd. 717, 219-225 (2017).

20. Cheng, S., Ma, E., Wang, Y. M. \& Kecskes, L. J. Tensile properties of in situ consolidated nanocrystalline Cu. Acta Mater. 53, 1521-1533 (2005).

21. Youssef, K. M., Abaza, M. A. \& Scattergood High strength, ductility, and electrical conductivity of in-situ consolidated nanocrystalline Cu-1\%Nb. Mater. Sci. Eng. A 711, 350-355 (2018).

22. Gupta, R. K., Darling, K. S. \& Singh Raman, R. K. Synthesis, characterization and mechanical behaviour of an in situ consolidated nanocrystalline FeCrNi alloy. J. Mater. Sci. 47, 1562-1566 (2012).

23. Varam, S., Prasad, M. D., Rao, K. B. S. \& Rajulapati, K. V. Mechanical properties of in situ consolidated nanocrystalline multi-phase $\mathrm{Al}-\mathrm{Pb}-\mathrm{W}$ alloy studied by nanoindentation. Philos. Mag. 96, 3671-3685 (2016).

24. Uesugi, T. \& Higashi, K. First-principles studies on lattice constants and local lattice distortions in solid solution aluminum alloys. Comput. Mater. Sci. 67, 1-10 (2013).

25. Esquivel, J., Wachowiak, M. G., O'Brien, S. P. \& Gupta, R. K. Thermal stability of nanocrystalline $\mathrm{Al}-5 \mathrm{at} . \% \mathrm{Ni}$ and $\mathrm{Al}-5 \mathrm{at} . \% \mathrm{~V}$ alloys produced by high-energy ball milling. J. Alloy. Compd. 744, 651-657 (2018).

26. Witharamage, C. S., Christudasjustus, J. \& Gupta, R. K. The effect of milling time and speed on solid solubility, grain size, and hardness of Al-V alloys. J. Mater. Eng. Perform. 30, 3144-3158 (2021). 
27. Witharamage, C. The Influence of Ball Milling Time on Solid Solubility, Grain Size and Hardness of Al-V Alloys. MS Thesis, The University of Akron (OhioLINK Electronic Theses and Dissertations Center, 2020).

28. Meng, Y. et al. Pitting of 2024 alloys prepared by spark plasma sintering using powders with different sizes. Corros. Sci. 170, 108525 (2020).

29. Huo, W. et al. Simultaneously enhanced mechanical strength and inter-granular corrosion resistance in high strength 7075 Al alloy. J. Alloy. Compd. 781, 680-688 (2019).

30. Moreto, J. A., Marino, C. E. B., Bose Filho, W. W., Rocha, L. A. \& Fernandes, J. C. S. SVET, SKP and EIS study of the corrosion behaviour of high strength $\mathrm{Al}$ and $\mathrm{Al}-\mathrm{Li}$ alloys used in aircraft fabrication. Corros. Sci. 84, 30-41 (2014).

31. Fattah-alhosseini, A. \& Sabaghi Joni, M. Semiconducting behavior of the anodically passive films formed on AZ31B alloy. J. Magnes. Alloy. 2, 305-308 (2014).

32. Liu, J. \& Macdonald, D. D. The passivity of iron in the presence of ethylenediaminetetraacetic acid. II. The defect and electronic structures of the barrier layer. J. Electrochem. Soc. 148, B425 (2001).

33. Scofield, J. H. Hartree-Slater subshell photoionization cross-sections at 1254 and 1487 eV. J. Electron Spectros. Relat. Phenom. 8, 129-137 (1976).

34. Strohmeier, B. R. An ESCA method for determining the oxide thickness on aluminum alloys. Surf. Interface Anal. 15, 51-56 (1990).

35. Tanuma, S., Powell, C. J. \& Penn, D. R. Calculations of electron inelastic mean free paths for 31 materials. Surf. Interface Anal. 11, 577-589 (1988).

36. Viroulaud, R. et al. Influence of surface pretreatments on the quality of trivalent chromium process coatings on aluminum alloy. Appl. Surf. Sci. 423, 927-938 (2017).

37. Li, M., Wiame, F., Seyeux, A., Marcus, P. \& Światowska, J. Effect of thermal oxidation on surface chemistry and elemental segregation of Al-Cu-Li alloy. Appl. Surf. Sci. 534, 147633 (2020).

38. Ambat, R., Davenport, A. J., Scamans, G. M. \& Afseth, A. Effect of iron-containing intermetallic particles on the corrosion behaviour of aluminium. Corros. Sci. 48 3455-3471 (2006).

39. lannuzzi, M., Young, T. \& Frankel, G. S. Aluminum alloy corrosion inhibition by vanadates. J. Electrochem. Soc. 153, B533 (2006).

40. lannuzzi, M. \& Frankel, G. S. Mechanisms of corrosion inhibition of AA2024-T3 by vanadates. Publ. Corros. Sci. 49, 2371-2391 (2007).

41. Natishan, P. M. Perspectives on chloride interactions with passive oxides and oxide film breakdown. J. Sci. Eng. 74, 263-275 (2018).

42. Natishan, P. M. \& O'Grady, W. E. Chloride ion interactions with oxide-covered aluminum leading to pitting corrosion: a review. J. Electrochem. Soc. 161, 421-432 (2014).

43. Yasakau, K. A., Zheludkevich, M. L. \& Ferreira, M. G. S. in Intermetallic Matrix Composites (ed. Mitra, R.) 425-462 (Woodhead Publishing, 2018).

44. Frankel, G. S. Pitting corrosion of metals: a review of the critical factors. J. Electrochem. Soc. 145, 2186-2198 (1998).

45. Patterson, A. L. The Scherrer formula for X-ray particle size determination. Phys. Rev. 56, 978-982 (1939).

46. Cullity, B. D. \& Stock, S. R. Elements of X-ray Diffraction 3rd edn (Pearson Education Limited, 2014).

\section{ACKNOWLEDGEMENTS}

The financial support from the National Science Foundation (NSF-CMMI 1760204 and NSF-CMMI 2131440) under the direction of Dr. Alexis Lewis is highly acknowledged. The authors would like to acknowledge the Analytical Instrument Facility (AIF) at North Carolina State University to facilitate the SEM, FIB, and XRD tests.

\section{AUTHOR CONTRIBUTIONS}

C.S.W. performed the experiments, including ball milling, SEM, XRD electrochemical tests, and data analysis, including TEM, XPS, and SIMS. J.C. conducted the XPS, SIMS, and TEM experiments and analyzed the resulting data. J.S. and W.G. helped in preliminary TEM data collection, R.K.G. conceptualized and supervised the whole study and received funding to perform the work. The manuscript was drafted by C.S. W., J.C., and R.K.G., and revised by all the authors.

\section{COMPETING INTERESTS}

The authors declare no competing interests.

\section{ADDITIONAL INFORMATION}

Supplementary information The online version contains supplementary material available at https://doi.org/10.1038/s41529-022-00225-5.

Correspondence and requests for materials should be addressed to R. K. Gupta.

Reprints and permission information is available at http://www.nature.com/ reprints

Publisher's note Springer Nature remains neutral with regard to jurisdictional claims in published maps and institutional affiliations.

Open Access This article is licensed under a Creative Commons Attribution 4.0 International License, which permits use, sharing, adaptation, distribution and reproduction in any medium or format, as long as you give appropriate credit to the original author(s) and the source, provide a link to the Creative Commons license, and indicate if changes were made. The images or other third party material in this article are included in the article's Creative Commons license, unless indicated otherwise in a credit line to the material. If material is not included in the article's Creative Commons license and your intended use is not permitted by statutory regulation or exceeds the permitted use, you will need to obtain permission directly from the copyright holder. To view a copy of this license, visit http://creativecommons. org/licenses/by/4.0/.

(c) The Author(s) 2022 